\title{
Reducing Global Neonatal Mortality Is Possible
}

\author{
Ola Didrik Saugstad
}

Department of Pediatric Research, Oslo University Hospital, Rikshospitalet, University of Oslo, Oslo, Norway

\section{Key Words}

Neonatal mortality • Millennium Development Goal 4 • Political will

\begin{abstract}
Background: The global neonatal mortality of $28 / 1,000$ live births is unacceptably high. Furthermore, the huge difference in mortality between high- and low-income countries and regions is presently one of the most burning human rights issues. The decline in neonatal mortality has been slow and is a main reason the Millennium Development Goal 4 does not seem to have been reached. Objectives: Several countries have shown it is possible to reduce neonatal mortality quickly and dramatically without much cost. Methods: It is important to learn from the successful countries and focus on the 3-4 major causes of neonatal death: asphyxia, infection, low birth weight/prematurity and congenital malformations. Results: A reasonable short-term goal is to reduce global neonatal mortality to $15 / 1,000$ which can be achieved without introduction of high technology medicine. A further reduction of mortality to $5 / 1,000$ should be the next global goal. Reaching this would reduce the present 3.8 million annual deaths by 3 million. In order to do this, regionalization of health care should be implemented. Maternal health should be the focus, with free antenatal care and centralized deliveries with health personnel attending the birth. Education of girls is perhaps the best way to prevent perina-
\end{abstract}

tal and neonatal deaths. Ten simple recommendations are given to reduce neonatal mortality. One of these is that each newborn baby in the world should have free access to essential drugs. Conclusions: It is possible to reduce newborn mortality in all countries and regions. Most important to achieve these goals is, however, political will.

Copyright $\odot 2010$ S. Karger AG, Basel

\section{Introduction}

In the global perspective, newborn mortality and morbidity are still very high. Between 1980 and 2000, neonatal mortality was reduced $25 \%$ only, and even less progress has been achieved in the 1st week of life. The slow decline in neonatal mortality, and especially early neonatal mortality, is the main reason the Millennium Development Goal (MDG) 4 to reduce child mortality $(<5$ year) by two thirds from 1990-2015 will not be reached [1]. With the present rate in reduction of child mortality, the MDG 4 will be reached 30 years later than the goal of the UN and other global organizations.

While a rapid increase in coverage of immunization has been seen and higher coverage has been developed for immunization and antenatal care, the same cannot be said of skilled or emergency care at birth and care of ill newborn babies [2]. Therefore, although the results of some of these campaigns have been striking $[3,4]$, this has not

\section{KARGER}

Fax +4161306 1234 E-Mail karger@karger.ch www.karger.com
Ola Didrik Saugstad, MD, PhD, FRCPE

Pediatrisk Forskningsinstitutt

Oslo Universitetssykehus, Rikshospitalet

Postboks 4950 Nydalen, NO-0424 Oslo (Norway)

Tel. +47 2307 2790/94, Fax +47 2307 2780, E-Mail odsaugstad@ rr-research.no 
Table 1. Key mortality figures in some selected countries 1990 and 2010

\begin{tabular}{lccc}
\hline Country & $\begin{array}{l}\text { Neonatal } \\
\text { mortality } \\
1990-2010[8]\end{array}$ & $\begin{array}{l}\text { Infant } \\
\text { mortality } \\
1990-2006[6]\end{array}$ & $\begin{array}{l}\text { Childhood } \\
\text { mortality } \\
1990-2006[6]\end{array}$ \\
\hline Bangladesh & $65-31$ & $100-52$ & $149-69$ \\
Cuba & $7.9-2.8$ & $11-5$ & $13-7$ \\
Chile & $9.2-3.8$ & $18-8$ & $21-9$ \\
Indonesia & $28-18$ & $66-26$ & $91-35$ \\
Malawi & $49-27$ & $131-76$ & $221-120$ \\
Oman & $19-7$ & $25-10$ & $31-11$ \\
Portugal & $8.3-1.9$ & $11-3$ & $14-4$ \\
Sri Lanka & $19-7$ & $26-11$ & $32-13$ \\
South Africa & $18-16$ & $45-56$ & $60-69$ \\
\hline
\end{tabular}

Neonatal mortality: deaths in the first 28 days of life per 1,000 live births with birth weight $>500 \mathrm{~g}$.

Infant mortality: deaths per 1,000 in the first year of life. Childhood mortality: deaths per $1,000<5$ years of age.

been enough to achieve the MDG 4. The primary strategy chosen by some charities and politicians to focus more on immunization campaigns than on newborn care was not based on strict scientific cost-benefit analyses $[4,5]$.

Key figures for child mortality of some selected countries are given in table 1 [6-8]. The latest information from the World Health Report indicates that approximately 4 million babies die worldwide in the neonatal period $[6,7]$. Fortunately, very recent reports indicate a more rapid decline in mortalities with the latest estimate being 3.1 million $(23 / 1,000)$ newborn deaths. This represents a $2.1 \%$ annual reduction in neonatal mortality between 1990 and 2010 [8]. Additionally, there are 2.3 million deaths both in the postneonatal period and in childhood (1-4 years of age) [8]. Worldwide mortality in children younger than 5 years has dropped from 11.9 million deaths in 1990 to an estimated 7.7 million deaths in 2010 , but is still only half of the annual decline of $4.4 \%$ needed in order to achieve MDG 4 [8].

In Norway and other high-income countries, there has been a gradual decline in neonatal mortality for at least the last 60-70 years. This decline is relatively linear and difficult to relate to specific medical progress, as for instance introduction of high technology and neonatal intensive care units. In Norway, neonatal mortality was 11.1/1,000 in 1967 before neonatal intensive care was developed in the whole country [9]. A global reduction to $15 / 1,000$ or even lower is therefore probably possible without high technology [10]. Such a reduction alone would save 2 million or more lives each year worldwide. A further global reduction to 5/1,000 neonatal deaths implies that 3 million lives would be saved annually. This is in my opinion a reasonable goal.

It is known that it is possible to reduce neonatal mortality quickly in virtually every region and country of the world if there is political will to do so and that it is possible without much extra cost, if any [11]. A reduction in mortalities is seen in poor areas as well. Many countries focus and give priorities to newborn care. Essential newborn care consists of resuscitation, prevention of hypothermia and infection, exclusive breastfeeding and referral of sick newborns.

In this article I summarize the present situation and experiences, and suggest some solutions and means of how to implement reduction in neonatal mortality. My main thesis is that neonatal mortality can be reduced relatively easily in all parts of the world within a short period of time without much cost. A reduction of the global neonatal mortality to $15 / 1,000$ is possible without introducing high technology medicine. A further reduction to $5 / 1,000$ is also possible without significant extra cost. Political will is, however, needed.

\section{Present Situation}

Global neonatal mortality is, according to the World Health Report, 28 per 1,000 live births [6]. There is a great variation between regions: Africa 40/1,000, Eastern Mediterranean 38/1,000, South-East Asia 35/1,000, the Americas 11/1,000 and Europe 10/1,000. The variation is even bigger between different countries from $1 / 1,000$ in Iceland and Singapore to 66/1,000 in Liberia. Income is an important determinant of death with 4/1,000 in high-income regions to 41/1,000 in low-income regions. Numbers for upper-middle $(12 / 1,000)$ and lower-middle income $(27 / 1,000)$ are in between. $99 \%$ of all neonatal deaths occur in low- or middle-income countries [6]. About 40\% of children $<5$ years who die are newborns. Of the almost 4 million newborns who die, between 25 and $50 \%$ die in the first $24 \mathrm{~h}$ and $75 \%$ die in the first week. Maternal and newborn health is one of the major health inequities of the world [1]. This huge inequity represents one of the largest gaps between rich and poor, and is perhaps more a human rights issue than a medical problem.

Globally there are 3 major causes of neonatal death: asphyxia (23\%), infections (36\%) and prematurity (28\%). Of the remaining, $7 \%$ are due to congenital malformations [12]. 
Sixty to $80 \%$ of neonatal deaths arise in low birth weight infants (birth weight $<2,500 \mathrm{~g}$ ). In high-income countries, infections play a less and less important role. In these countries, congenital malformations, relatively speaking, are becoming more important as a cause of neonatal death. It is well known that the 3 first causes listed are closely related. Asphyxia is more common if there is an infection, as are low birth weight and prematurity. Furthermore, these conditions very often are related to the health condition of the pregnant women. If malnourished she more easily attracts infections, lowering the growth rate and triggering a preterm delivery. Such fetuses are also more susceptible to birth asphyxia. Therefore, it is clear that maternal health and newborn health are closely interwoven. Newborn health can therefore not be improved without improving the mother's health [13-15]. Proper nutritional status may prevent infections, and thus prevent preterm delivery, birth asphyxia and prematurity. Optimal birth conditions must therefore be organized. Focusing on the 3 major causes of death is a successful way to reduce neonatal deaths.

\section{Maternal Factors}

Maternal deaths represent one of the biggest risk factors for newborn death, thus making a healthy mother essential for good newborn care [16].

\section{Maternal Nutritional Status}

Maternal undernutrition is associated with an increased risk of infections, preterm birth and intrauterine growth retardation. Obesity and gestational diabetes mellitus as well as type 2 diabetes mellitus are associated with large-for-gestational age babies and congenital malformations. Folate given periconceptionally reduces the risk of neural tube defects and cleft palate. Maternal multimineral nutrition supplementation, as compared with iron and folic acid supplementation alone, reduced neonatal mortality and fetal loss [17]. Balanced energy and protein supplementation during pregnancy is important; however, it is more important to achieve maternal weight gain before pregnancy in undernourished women. A high protein supplementation diet during pregnancy is not recommended for such women [18]. Maternal stress and depression also increase the risk of preterm birth, possibly through the corticotrophin-releasing hormone and inflammatory pathways initiating labor. Teenage pregnancies also increase preterm births and fetal growth restriction. Smoking reduces birth weight, and a series of birth defects and developmental delay is associated with alcohol consumption and drug abuse [19].

Educating girls seems to be perhaps the best way to prevent maternal and child mortality and morbidity.

\section{Labor Complications}

Intrapartum risk factors are associated with greater risk of neonatal death than prepartum risk factors. Obstructed labor and malpresentation gives the highest risk. Breech presentation and obstructed labor increases risk of neonatal death more than 6 -fold. Maternal fever during labor and meconium-stained amniotic fluid increase the odds ratio for neonatal death by about 10 times [1].

\section{Birth Asphyxia}

Birth asphyxia or intrapartum-related neonatal deaths is globally the 5th most common cause of deaths among children under 5 years. It is estimated that 6-7 million, or even more, would need some form of intervention or resuscitation at birth with approximately $1 \%$ of all births requiring extensive resuscitation, i.e. 1.3 million infants each year [20]. Four million newborn infants go through birth asphyxia each year, accounting for an estimated 904,000 deaths and 42 million disability-adjusted life years [21].

An equal number develop sequelae following birth asphyxia, most commonly cerebral palsy, epilepsy or sensory deficit [22].

Several programs have been developed in different parts of the world in order to prevent birth asphyxia. Many new resuscitation programs have been developed or are about to be implemented. These are based on simple algorithms in which ventilation of the baby is the cornerstone. Such programs were able to be developed when it was demonstrated that newborn infants can be easily (and probably better) resuscitated with ambient air. Supplemental oxygen is therefore not needed in order to establish such programs. The WHO implemented this knowledge already in 1998 in its guidelines for 'Basic Newborn Resuscitation' [23] - guidelines which will be renewed in 2010/11. By using ambient air and avoiding the use of $100 \%$ oxygen for newborn resuscitation, a Cochrane review as well as a recent meta-analysis concluded that around 200,000 lives, approximately $30 \%$, may be saved [24].

In a recent study identifying research priorities for birth asphyxia, the top one third of 61 ranked research investment options were dominated by delivery research 
(implementation), while discovery science questions were not ranked highly, especially for reduction of mortality and inequity. These results indicate a mismatch between current research investments and those most likely to result in accelerated progress towards MDG 4 in the countries where the most deaths occur [21].

\section{Low Birth Weight}

There are a number of risk factors for low birth weight, such as poor socioeconomic conditions, very young maternal age, poor diet (inadequate caloric intake, nutritional deficiencies of iron, folate and zinc), cigarette smoking and infections. Low birth weight was defined by the World Health Assembly in 1976 as weight $<2.5 \mathrm{~kg}$. One problem with birth weight as an outcome variable is that only about half of the world's babies are weighed at birth. Estimates indicate there are 20 million low birth weight newborn babies each year - $15 \%$ of all deliveries - with about $95 \%$ occurring in low-income countries [1]. In some countries, low birth weight and prematurity are increasing [25].

There is a wide variation between countries. Finland for instance has $4 \%$ compared to Bangladesh and India with $30 \%$ low birth weight infants. An analysis of trends in low birth weight is difficult because of lack of comparability of estimates over time. The incidence of low birth weight in developing countries consists of nearly one fourth of the newborns; 24\% in 1990 and 23\% 10 years later [26]. Still, some regions and countries have been successful in reducing low birth weights. For instance, in Cuba these have fallen from $10.4 \%$ in 1978 to $5.4 \%$ in 2005 [19]. The main causes of low birth weight are prematurity and fetal growth restriction.

A recent article by Beck et al. [27] for the first time estimates the global incidence of preterm birth. Worldwide the prematurity rate is $9.6 \%$, representing 12.9 million births. The highest prematurity rates are found in Africa and North America with $11.9 \%$ and $10.6 \%$, respectively. Approximately $85 \%$ (10.9 million) of the premature births are found in Africa and Asia. In the more developed countries, the prematurity rate is $7.5 \%$ compared to $12.5 \%$ in the least developed countries [27].

Based on the recent finding of prematurity rate, approximately 7-8 million babies may be growth retarded, although these estimates are uncertain. In the USA, the infant mortality rate is increased 25 times in low birth weight babies. Even for babies with birth weights between 2.25 and $2.5 \mathrm{~kg}$, the infant mortality is almost 5 times greater than for babies weighing $>2.5 \mathrm{~kg}$. An increase in $100 \mathrm{~g}$ in mean birth weight is associated with a $30-50 \%$ reduction in neonatal mortality $[28,29]$.

\section{Infections}

More than 1 million newborns die of infections each year. Most of these occur in the late neonatal period. Preterm births are associated with asymptomatic genital and urinary tract infections. There are conflicting results with antibiotic treatment regarding prevention of premature labor [30, 31].

Vaginal vaginosis, genital infections by chlamydia, gonorrhea and group B streptococcus acquired from a colonized birth canal may infect the newborn during delivery resulting in high morbidity and mortality. The APPLe study, however, did not show any benefit of prophylactic azithromycin regarding prevention of preterm birth in a district of Malawi with a high prevalence of preterm births [31]. The authors of that study also carried out a meta-analysis showing no effect of prophylactic antibiotics on prematurity. If premature rupture of membranes occurs, it seems that antibiotics have some protective effects early and less so closer to term [32]. A recent Cochrane review concluded that the decision to prescribe antibiotics for women with premature rupture of membrane is not clear cut. Benefits in some short-term outcomes should be balanced against a lack of evidence of benefit for others, including perinatal mortality and long-term outcomes [33].

The importance of access to health care and antibiotic therapy is demonstrated by the fact that the majority of neonates who die of infections do so because of a lack of these.

\section{Congenital Malformations}

The relative importance of congenital abnormalities as a cause of neonatal deaths increases when other causes of death are reduced. In countries with low neonatal mortality, congenital malformations constitute a bigger part of deaths than in countries with high neonatal mortality. In Norway congenital malformations constitute 39\% of newborn deaths, but less than 1/1,000 live births [9]. Still the number of congenital malformations decrease in high-income countries due to better care (e.g. prevention of myelomeningocele and cleft lip by folic acid) and improved surgical services, as well as liberal abortion practices of malformed fetuses. 


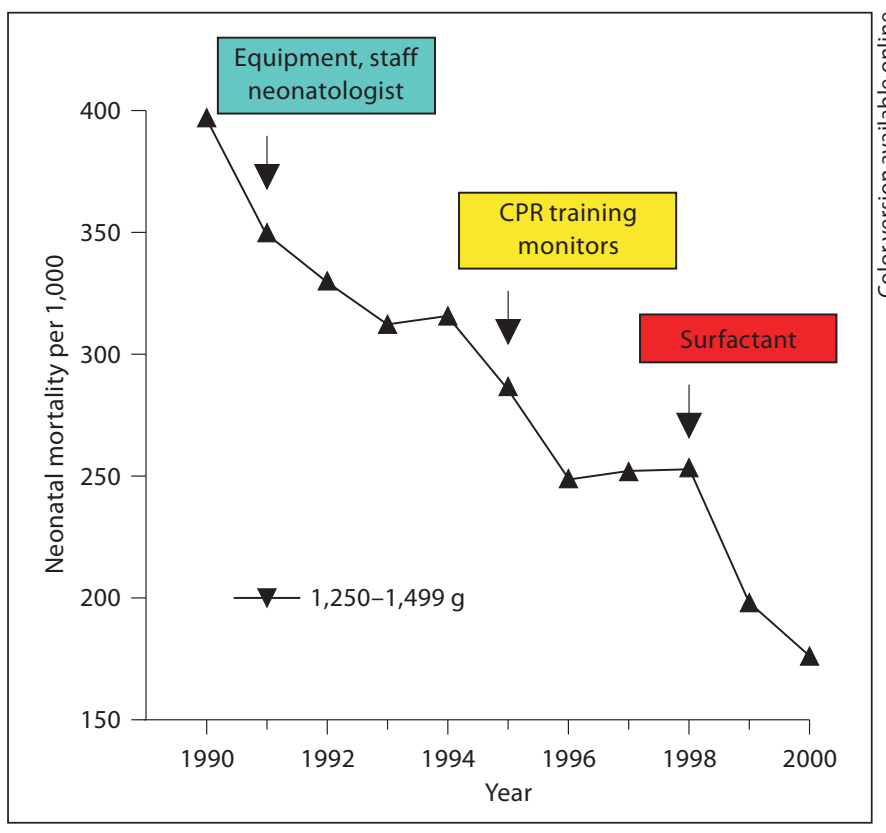

Fig. 1. Reduction in neonatal mortality in Chile for newborns with birth weights 1,250-1,500 g between 1990 and 2000. Different interventions are marked. Data are adapted from Gonzalez et al. [37]. CPR = Cardiopulmonary resuscitation.

\section{The Experience from Some Countries}

A number of countries can be mentioned as successful examples of a rapid reduction in newborn, infant and under 5-year mortality. Some of them are listed in table 1 , such as Oman which has achieved a remarkable reduction in neonatal mortality. The table also includes a middle-income country, South-Africa, with no reduction in mortality, mainly due to the HIV/AIDS epidemic.

\section{The Cuban Experience}

The fraction of low birth weight infants in Cuba has been halved from 1978 to 2005 , in contrast to increases in several other countries [19]. The primary health care system is based on family doctors and nurses located in primary care centers. A thorough knowledge of each family enables the health care providers to give appropriate advice regarding nutrition to women already before conception. A comprehensive antenatal check-up system contributes to the Cuban results $[19,34]$. The low fertility rate alongside the availability of abortion on request with a high abortion rate of 20.9 per 1,000 women in Cuba with a decreasing live birth rate are major contributing factors to the low neonatal mortality in Cuba [35]. Another important contributing factor is free education from the age of 6 years for a minimum of 10 years for all girls with the result that all pregnant women are educated.

\section{The Portuguese Miracle}

Thirty years ago Portugal had high neonatal and infant mortality. Today, infant mortalities there is among the lowest in the world. In 1989 a reform was initiated. Maternal wards with less than 1,500 annual deliveries were closed down and a regionalized system with classifications of level I, II and III were introduced. A nationwide transport system for pregnant women and newborn babies was established, and training of personnel was intensified with postgraduate education in neonatology. 150 maternal wards were closed, reducing delivery units from 200 to 50 . In spite of that, in-hospital deliveries increased from 74 to $99 \%$ after the reform. The maternal death rate decreased from 9.2 per 100,000 in 1989 to 5.3 in 2003. Perinatal mortality decreased from 16.4 to 6.6 per 1,000. Infant mortality decreased from 12.2 to 4 per 1,000 and neonatal mortality from 8.1 to 2.7 per 1,000 . This remarkable reduction in mortalities was accomplished virtually without any extra costs [36].

\section{The Chilean Success Story}

In Chile the neonatal mortality has sharply declined from 1990 to today, from 8.3/1,000 in 1990 to 5.7/1,000 in 2000. In 2004 it was further reduced to 5.0/1,000. For babies with birth weights between 1,250 and $1,500 \mathrm{~g}$, the reduction was from 400 to approximately 200 per 1,000 [37]. The decline in mortalities in Chile followed 2 phases. The first one which started in the 1950s with the establishment of the National Health Service largely influenced mortality by poverty reduction. The main scope of action of this public health system was maternal and child health. In the following 40 years, infant mortality decreased from 136 to 16 per 1,000 live births. In 1990 a 2nd phase was introduced which focused on health care interventions [38]. In 1991 Chile strengthened the neonatologist staff and introduced new equipment in the neonatal intensive care units. In 1994 they introduced monitors in the neonatal intensive care units and training in cardiopulmonary resuscitation. In 1998 surfactant was introduced on a national level [37]. Figure 1 demonstrates a decrease in neonatal mortality for birth weights between 1,250 and 1,500 g in Chile between 1990 and 2000. Although a decrease in mortality was noted before interventions, a faster decline in mortality is associated to certain interventions as mentioned above.

Still more importantly than these interventions may have been the reduction in inequalities and elimination 
of poverty. The health gap between poor and rich has been dramatically reduced [39]. This has probably played a major impact on neonatal mortality. Thus, the difference between the 1st and 5 th quintiles (that is between the richest and poorest quintiles) in neonatal mortality was reduced from 41 to $19 \%$ between 1990 and 2004. Similar reductions were found regarding all other mortality indicators as maternal, perinatal, infant and child mortalities.

\section{Experiences from the Indian Subcontinent}

In the Indian subcontinent, both Bangladesh and Sri Lanka have obtained remarkable results. From 1990 to 2010, neonatal mortality was reduced from 65 to 31/1,000 in Bangladesh and from 19 to 7/1,000 in Sri Lanka (table 1). In Gujarat in India with 55 million inhabitants, great success has been accomplished by contracting private obstetricians/gynecologists to provide delivery care to the poor in the rural areas. A salary of USD 46 per delivery including handling of complications was offered. 800 obstetricians participated in the project and 176,000 poor women delivered in hospitals (27\% in 2005 to $53 \%$ in 2007) [40].

Maternal deaths were estimated to fall from 384 to 32 (a more than 90\% reduction). Neonatal deaths before were estimated to be 8,462 and 559 after the initiation of this project, an almost $95 \%$ reduction. If this principle were to be applied to the whole country with 27 million births, the cost would only be an estimated USD 250 million.

\section{Interventions}

These examples demonstrate it is possible to reduce neonatal mortality by simple means. In addition to the medical aspects, an optimal infrastructure with clean water, sanitation and transport systems should be emphasized. The best security for the fetus and the newborn child is probably an educated mother. Free education of girls therefore should be given top priority. Free access to antenatal and postnatal care is essential. Recently, a metaanalysis showed that kangaroo mother care reduces neonatal deaths and morbidity in babies with birth weight $<2,000 \mathrm{~g}$ [41]. Another study from rural communities in Argentina, Democratic Republic of Congo, Guatamala, India, Pakistan and Zambia did not, however, show any reduction in short-term neonatal mortality before and after introduction of so-called essential newborn care intervention [42].

The following interventions have recently been identified to have moderate- to high-quality evidence and are
Table 2. Medical recommendations for reducing newborn mortality

1 Learn from other countries

2 Regionalization and classification of care levels

3 Easy and free access to pre- and postnatal care

4 Encourage hospital deliveries

5 Promote breastfeeding

6 Invest in equipment (monitors, incubators) and staff

7 Evidence-based treatment and guidelines

8 National and international neonatal networks

9 Free essential drugs for all pregnant women and children

10 Training programs and research

now strongly recommended in order to improve outcomes of term and preterm newborns in low- and middle-income countries [43, 44]:

(1) antenatal steroids in preterm labor;

(2) antibiotics for premature rupture of membranes;

(3) vitamin K;

(4) case management for neonatal sepsis and pneumonia;

(5) delayed cord clamping;

(6) room air resuscitation instead of $100 \%$ oxygen;

(7) hospital-based kangaroo mother care;

(8) early breast feeding;

(9) thermal care;

(10) surfactant therapy; and

(11) application of continued distending pressure to the lungs for respiratory distress syndrome.

Two interventions for preventing preterm birth (smoking cessation and progesterone) are also mentioned [44].

Based on these facts and experiences, it should be possible to create simple algorithms that may guide each country in its efforts to reduce newborn mortality and morbidity. I have put together the following basic medical recommendations for success in reducing neonatal mortality (table 2).

Preconception care with at least 4 prenatal visits, intrapartum and postnatal care are of importance. Breast feeding is one of the most important factors to reduce neonatal morbidity and mortality. This also has longterm consequences on intellectual and motor development, and diseases in adult life.

The last item, free essential drugs to all pregnant women and children should be demanded from the politicians by every perinatologist all over the world. Every pregnant woman and newborn in need of essential drugs should have access to these. 


\section{Discussion}

A child's risk of dying is highest in the 1st month of life, when safe childbirth and effective neonatal care are essential. Preterm and low-weight birth, birth asphyxia, and infections cause most newborn deaths. Experience from several countries and regions teach us that neonatal mortality can quickly and easily be reduced in virtually every part of the world, even in low-income countries.

A number of factors may contribute to reducing neonatal and childhood mortality. Beyond the factors focused in this article, infrastructure has to be improved by clean water, sanitation and transport. In countries with a high neonatal mortality, it is most important to influence such environmental factors as typical for poverty. In a 2nd phase, medical interventions may be more important [38]. Therefore, public health issues are of great significance in relation to neonatal mortality. Reduction of socioeconomic inequalities and education, especially of girls, are major means to reduce neonatal and childhood mortalities.

In South Africa, for instance, the HIV/AIDS epidemic has contributed strongly to the lack of reduction in infant and childhood mortality. Contributing to the Cuban results is the falling fertility rates as a consequence of a liberal abortion policy.

In order to facilitate a reduction in neonatal and childhood mortality, it is important to learn from other countries. However, each country also has to find its own solutions. Chile is a country where $40 \%$ of the population is gathered in one city and therefore not representative for countries with a more dispersed population. Although there was success in Portugal when it closed down smaller maternity units, it may not be wise to shift babies to bigger regionalized centers with better equipment and medical staff in many low-income countries without developed transportation systems.

In spite of the fact that South Africa has provided free antenatal care since 1995, a substantial number of pregnant women fail to make use of this offer. Several factors have been identified as to why pregnant women do not use this offer. These include tardiness, unawareness of pregnancy, too busy working or studying, fear of parents knowing of the pregnancy, and negative attitudes of nursing staff towards adolescent pregnant women. Interestingly, sociodemographic factors such as level of education and employment status did not influence the women's booking pattern. In spite of it being free, some costs such as transportation and loss of income may prevent women from using the free antenatal care [45].
Each country needs a registry to carefully follow development in mortality rates. Perinatal audits are also recommendable. Common and identical definitions of the different mortality parameters should be used. International networks also stimulate to improvements, and national perinatal societies may improve collaboration across different fields. A regionalized system with a classification of level of care seems to be needed in order to accomplish progress. This means that in countries with private hospitals and health care institutions, these must be part of a general public health plan. Research should be performed on all levels [46].

Deliveries should be centralized if possible, the degree of which is dependent on infrastructure such as roads and transport systems, and access to health workers. There must be a wide variation adjusted to the local needs. As mentioned, it may not be appropriate to close down smaller maternity units in many larger low-income countries with sparsely populated areas if the infrastructure is not in place with roads and adequate transportation.

A short-term goal should be to reduce global neonatal mortality to $15 / 1,000$. This is possible to reach without introduction of high-technology medicine. A further reduction to 5/1,000 is in reach of every country and region without much extra cost [47].

According to the WHO, at least 200 million children globally are not achieving their full potential, which has huge implications not only for the individual but also for the society at large. Investment in early years provides great potential for reducing health inequities [48]. The most important factor to successfully reduce neonatal mortality is political will. We know how to do it; we know it is possible within a short period of time at a low cost, provided there is political will. It is time we require that the politicians act.

\section{Acknowledgments}

Dr. Mario Merialdi and Dr. Rogelio Gonzalez kindly read through the manuscript and gave valuable input. The author has no conflict of interests to declare.

References

Saugstad

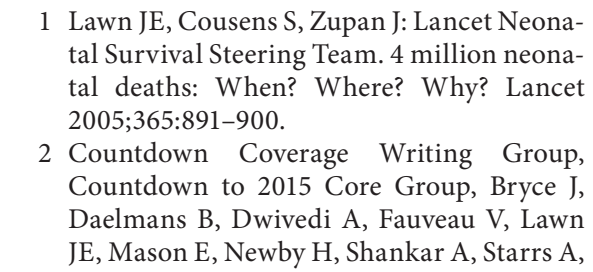
JE, Mason E, Newby H, Shankar A, Starrs A, 
Wardlaw T: Countdown to 2015 for maternal, newborn, and child survival: the 2008 report on tracking coverage of interventions. Lancet 2008;371:1247-1258.

>3 Clements CJ, Nshimirimanda D, Gasasira A: Using immunization delivery strategies to accelerate progress in Africa towards achieving the Millennium Development Goals. Vaccine 2008;26:1926-1933.

4 Stoltenberg J: Delivering for women and children. Lancet 2008;12:1230-1232.

5 Janson A: Shed some light on darkness: will Tanzania reach the millennium development goals? Acta Paediatr 2007;96:781-786.

6 WHO: World Health Statistics. Geneva, WHO, 2008.

7 UNICEF: The State of the World's Children. New York, UNICEF, 2008.

$>8$ Rajaratnam JK, Marcus JR, Flaxman AD, et al: Neonatal, postneonatal, childhood, and under-5 mortality for 187 countries, 19702010: a systematic analysis of progress towards Millennium Development Goal 4. Lancet 2010;375:1988-2008.

9 Medical Birth Registry of Norway. Births in Norway through 30 Years. Bergen, 1997.

10 Macfarlane A, Mugford M: Epidemiology; in Rennie JM (ed): Roberton's Textbook of Neonatology, ed 4. New York, Churchill Livingstone, 2005.

-11 Johns B, Sigurbjörnsdóttir K, Fogstad H, Zupan J, Mathai M, Tan-Torres Edejer T: Estimated global resources needed to attain universal coverage of maternal and newborn health services. Bull World Health Organ 2007;85:256-263.

-12 Lawn JE, Wilczynska-Ketende K, Cousens SN: Estimating the causes of 4 million neonatal deaths in the year 2000. Int J Epidemiol 2006;35:706-718.

-13 Morrison J, Bhutta Z, Perry H, Rifkin S, Costello A: Community participation: lessons for maternal, newborn, and child health. Lancet 2008;372:962-971.

-14 Lawn JE, Kerber K, Enweronu-Laryea C, Massee Bateman O: Newborn survival in low resource settings - are we delivering? BJOG 2009;116(Suppl 1):49-59.

15 Bhutta ZA, Darmstadt GL, Hasan BS, Haws RA: Community-based interventions for improving perinatal and neonatal health outcomes in developing countries: a review of the evidence. Pediatrics. 2005;115(2 Suppl):519-617.

-16 Bhutta ZA, Chopra M, Axelson H, et al: Countdown to 2015 decade report (200010): taking stock of maternal, newborn, and child survival. Lancet 2010;375:2032-2044.

-17 The Supplementation with Multiple Micronutrients Intervention Trial (SUMMIT) Study Group: Effect of maternal multiple micronutrient supplementation on fetal loss and infant death in Indonesia. A doubleblind cluster-randomized trial. Lancet 2008; 371:215-227.

Reducing Global Neonatal Mortality Is Possible
18 Kramer MS, Kakuma R: Energy and protein intake in pregnancy. Cochrane Database Syst Rev 2003:CD000032.

19 Lopez NB, Choonara I: Can we reduce the number of low-birth-weight babies? The $\mathrm{Cu}$ ban experience. Neonatology 2009;95:193197.

20 UNICEF: Child Health Mortality Statistics. New York, Unicef, 2003.

21 Lawn JE, Bahl R, Bergstrom S, et al: Setting research priorities to reduce one million deaths from 'birth asphyxia' by 2015. PloS, submitted.

22 World Health Organization. The World Health Report 2005 - Make Every Mother and Child Count. WHO, Geneva, 2005.

23 WHO: Basic Newborn Resuscitation; A Practical Guide. Geneva, WHO, 1998.

24 Saugstad OD, Ramji S, Soll RF, Vento M: Resuscitation of newborn infants with 21 or $100 \%$ oxygen: an updated systematic review and meta-analysis. Neonatology 2008;94: 176-182.

25 Keller M, Felderhoff-Mueser U, Lagercrantz H, Dammann O, Marlow N, Hüppi P, Buonocore G, Poets C, Simbruner G, Guimaraes H, Mader S, Merialdi M, Saugstad OD: Policy benchmarking report on neonatal health and social policies in 13 European countries. Acta Paediatr 2010;99:1624-1629.

26 UNICEF/WHO. Low Birthweight: Country, Regional and Global Estimates. UNICEF, New York, 2004

27 Beck S, Wojdyla D, Say L, Betran AP, Merialdio M, Requejo JH, Rubens C, Menon R, Van Look PFA: The worldwide incidence of preterm birth: a systematic review of maternal mortality and morbidity. Bull World Health Organ 2010;88:31-38.

28 Goldenberg RL, Culhane JF, Iams JD, Rome ro R: Epidemiology and causes of preterm birth. Lancet 2008;371:75-84.

29 Shrimpton R: Reducing childhood mortality in poor countries. Preventing low birth weight and reduction of child mortality. Trans R Soc Trop Med Hyg 2003;97:39-42.

-30 Villar J, Gulmezoglu M, Metin A, de Onis M: Nutritional and antimicrobial interventions to prevent preterm births: an overview of randomized controlled trials. Obstet Gynecol Surv 1998;53:575-585.

31 van den Broek NR, White SA, Goodall M, Ntonya C, Kayira E, Kafulafula G, Neilson JP: The APPLe study: a randomized, community-based, placebo-controlled trial of azithromycin for the prevention of preterm birth, with meta-analysis. PLoS Med 2009; 6:e1000191.

32 Petraglia F, Visser GH: Prevention and management of preterm labour. J Matern Fetal Neonatal Med 2009;22(Suppl 2):24-30.

33 Kenyon S, Boulvain M, Neilson JP: Antibiotics for preterm rupture of membranes. Cochrane Database Syst Rev 2010;8:CD001058.

$>34$ Rodriguez FV, Lopez NB, Choonara I: Child health in Cuba. Arch Dis Child 2008;93:991993.
35 Acosta D: Abortion competes with contraceptives. http://ipsnews.net/news.asp? idnews $=33458$.

36 Neto MT: Perinatal care in Portugal: effects of 15 years of a regionalized system. Acta Paediatr 2006;95:1349-1352.

>37 Gonzalez R, Merialdi M, Lincetto O, Lauer J, Becerra C, Castro R, García P, Saugstad OD, Villar J: Reduction in neonatal mortality in Chile between 1990 and 2000. Pediatrics 2006;117:e949-e954.

38 Jimenez, J, Romero MI: Reducing infant mortality in Chile: success in two phases. Health Affairs 2007;26:458-465.

>39 Gonzalez R, Requejo JH, Nien JK, Merialdi M, Bustreo F, Betran AP, Chile Maternal, Newborn, and Child Health Writing Group: Tackling health inequities in Chile: maternal, newborn, infant, and child mortality between 1990 and 2004. Am J Public Health 2009;99:1220-1226.

40 Mavalankar D, Singh A, Patel SR, Desai A, Singh PV: Saving mothers and newborns through an innovative partnership with private sector obstetricians: Chiranjeevi scheme of Gujarat, India. Int J Gynaecol Obstet 2009; 107:271-276

-41 Lawn JE, Mwansa-Kambafwile J, Horta BL, Barros FC, Cousens S: 'Kangaroo mother care' to prevent neonatal deaths due to preterm birth complications. Int J Epdemiol 2010;39(Suppl 1):i144-i154.

$\checkmark 42$ Carlo WA, Goudar SS, Jehan I, et al: Newborn-care training and perinatal mortality in developing countries. N Engl J Med 2010; 362:614-623.

43 Sayers S: Indigenous newborn care. Pediatr Clin N Am 2009;56:1243-1261.

44 Barros, FC, Bhutta ZA, Batra M, Hansen TN, Victoria CG, Rubens CE, GAPPS review group: Global report on preterm and stillbirth ( 3 of 7): evidence for effectiveness of interventions. BMC Pregnancy and Childbirth 2010;10(Suppl 1):S3.

45 Sibeko S, Moodley J: Healthcare attendance patterns by pregnant women in Durban, South Africa. SA Fam Pract 2006;48:17, a-e.

46 Bahl R, Martines J, Ali N, Bhan MK, Carlo W, Chan KY, Darmstadt GL, Hamer DH, Lawn JE, McMillan DD, Mohan P, Paul V, Tsai AC, Victora CG, Weber MW, Zaidi AK, Rudan I: Research priorities to reduce global mortality from newborn infections by 2015 . Pediatr Infect Dis J 2009;28(1 Suppl):S43S48.

47 Adam T, Lim SS, Mehta S, Bhutta ZA, Fogstad H, Mathai M, Zupan J, Darmstadt GL: Cost effectiveness analysis of strategies for maternal and neonatal health in developing countries. BMJ 2005;33:1107.

48 Commission on Social Determinants of Health. Closing the Gap in a Generation: Health Inequity through Action on the Social Determinants of Health. Final Report of the Commission on Social Determinants of Health. WHO, Geneva, 2008. 